Adamu Jamilah, Md.Imdadul Haque1, Faisal Muhammad, Md. Golam Dostogir Harun', A.B. M. Alauddin Chowdhury¹, Md. Akramuzzaman², S.M. Yasir Arafat ${ }^{3}$, Russell Kabir ${ }^{4 *}$

\title{
Depression and Associated Factors among International Students in a Private University of Bangladesh
}

\author{
'Department of Public Health, Daffodil International University, Mirpur Road, Dhanmondi, Dhaka 1207, Bangladesh \\ 2Department of History, Jagannath University, Dhaka 1100, Bangladesh \\ ${ }^{3}$ Department of Psychiatry, Enam Medical College and Hospital, Dhaka-1340, Bangladesh \\ «School of Allied Health, Anglia Ruskin University, Essex, UK \\ *email: russell.kabirdaru.ac.uk \\ DOI: 10.2478/gp-2020-0021 \\ Received: 8 July 2020; Accepted: 11 August 2020
}

\begin{abstract}
Background: Depression is the second major cause of disability and is a principal source of disease burden worldwide which is quite common among international students.
\end{abstract}

Aim: This study explored the depression and its associated factors among international students of a private university in Bangladesh.

Methods: This cross-sectional study was conducted among 149 international students at a private university in Dhaka, Bangladesh using the Center for Epidemiologic Studies Depression (CES-D 10) Scale.

Results: The prevalence of depressive symptoms among international students was 47.7\%. Students' age, marital status, satisfaction with living conditions and problems concerning studies, food, homesickness, finances, accommodation, and health were significantly associated with depression.

Conclusion: This study concluded that there is an unmet need for psychological support for international students studying in Bangladesh. Appropriate support services should be directed to them to help and to overcome the challenges they face.

\section{Keywords}

International Students, Depression, Bangladesh, Private University, Factors

\section{INTRODUCTION}

Depression is an illness that involves the body, mood and thoughts (Khan et al., 2006). It is a common mental disorder characterized by sadness, loss of interest or pleasure, feelings of guilt or low self-worth, disturbed sleep or appetite, feelings of tiredness and poor concentration, are a leading cause of disability and a significant source of the burden of disease worldwide (WHO, 2018).

International students are those who travel to a country different from their own for tertiary study (OECD, 2013). The number of students enrolled in tertiary education outside their country of citizenship has sharply increased over the last few decades, reflecting the expansion of tertiary education systems worldwide and the globalization of economies and societies. Currently, over five million students are studying outside their home countries, more than double the 2.1 million who did so in 2000 and more than triple the number in 1990 (OECD, 2013). Several pieces of research among International Students have shown a high prevalence of depression (Khawaja et al., 2007; Hahn, 2010; Ibrahim et al., 2013; Eskanadrieh et al., 2012). International students are inclined to experience depression while pursuing their programs of study in other countries due to the myriad challenges they have to face. International students face not only the same life events and stressors as other students, which can have an impact upon their mental health, but they also face additional pressures, all without the usual support structures of family, friends and home. They face financial concerns, uncertain immigration status, language barriers and perceived discrimination above and beyond the typical difficulties associated with university life. Also, students need to learn the norms and the languages of host countries, meet the rigours of academic coursework, live 
alone, and manage finances, not to mention that they have to sometimes contend with homesickness and racial prejudice and discrimination (Lee et al., 2013).

Those students, who are less resilient to adversity, change and loss before leaving their home countries will tend to experience greater difficulty in adjusting to life and study abroad. Research on the factors associated with depressive symptoms among International students can provide added insight into the extent of this illness among the subpopulation and shed more light on identities of vulnerable members and help make mental health interventions more effective to reach out to support such people in greatest need and to mount support for them.

Most research on the mental health of international students has been done in developed countries, and this has been used to inform the design of student counselling and support services, and to evaluate the effectiveness of mental health services in the western context. Every year, a good number of international students come to Bangladesh to pursue their education and no research has been done so far on them. This is the first research in the South East Asia region to gain insight into the influence of stress or problems on the mental well-being and academic performance of international students in a private University. In order to capture the nature of the issues encountered by international students, the research includes parts on academic achievement and problem-related information to find out stressors that are more specific to international students. The objective of the study is to find out the prevalence of depressive symptoms among international students, as well as factors associated with depressive symptoms in a private university in Dhaka, Bangladesh.

\section{MATERIALS AND METHODS}

\section{Sampling and Data Collection}

A cross-sectional survey was conducted among the international students who were enrolled at a private university in Dhaka, Bangladesh at time of the study (December 2015 to March 2016). During this period, the university had 181 international students out of over 16,000 students. The inclusion criteria used for the survey were: international students involved in the study were not citizens and were not permanent residents of Bangladesh and came to the country to complete a program of study. The whole population of international students was targeted to be part of the study conveniently. At the time of data collection, each student had sat for at least one examination since admission.

\section{Questionnaire}

The survey was carried out by a self-administered structured pre-tested questionnaire. Questionnaires were distributed to the students in their classes. The questionnaire was in four parts: Socio-demographic data, problem-related data, academic performance and the short CES-D Scale for the measurement of depression.

Variables in the socio-demographic data included gender, age, marital status, country of origin, Degree category, source of funding, residential arrangements and satisfaction with living conditions. Problems or stressor variables include issues with adapting to food, accommodation, health and financial difficulty, perception of comfortable living as well as the effect of family issues or homesickness. Academic related variables include perceptions of problems regarding study at the university, quality of the study, teachers' cooperation, attendance of classes and exams, as well as current Grade points (CGPA) of the students.

The CES-D-R Scale for depression: The short-revised version of the CESD scale contains ten items to measure depressive symptoms. Each item has four scored responses from 'rarely' or 'none of the time' to 'most' or 'all the time' to form a 4-point Likert-like scale. A score of 10 is the cut off for depression with scores ranging from 0 to 30 . Considered with depressive symptoms are students who score ten or more on the short CES-D Scale. The CESD-10, when compared to four other abbreviated versions of the CES-D, had the most robust psychometric properties, with acceptable reliability, sensitivity and specificity, suggesting that it can serve as a useful measure for mental health without sacrificing precision compared to the full CES-D (Thakar, 2010; CESD-R, 2004).

Data Analysis: Questionnaire was coded before entering the data to the computer by the Researcher. The sample database was checked for incomplete questionnaires, which were excluded from the research. For data analysis, the Statistical Package for the Social Sciences (SPSS version 16) was used. Descriptive statistics such as frequency, percentage, mean and standard deviation were applied for general sociodemographic characteristics, the prevalence of depression and problems description. Pearson's correlation was used to find the relationship between two quantitative variables of Age and CESD score. Bi-variate analysis (Chi-square test and Fisher's exact test) were used to test the relationship between depressive symptoms and the students' socio-demographic factors and problems encountered. Testing of all hypotheses was performed at $5 \%$ level of significance. 


\section{Ethical considerations}

The study was approved by the academic committee of the Department of Public Health of Daffodil International University. Informed consent was obtained from the participants. The initial letter of the questionnaire included a clear explanation of the study objectives and assured the participants regarding the anonymity as well as the confidentiality of the information. Students were then invited to complete the questionnaire and were informed that they could stop answering the questions in the event of discomfort. Students were thanked for their participation. No incentive of any form was given.

\section{RESULTS}

A total of 152International students completed the questionnaires yielding $84 \%$ response rate. Three questionnaires were excluded due to incomplete response leaving 149 questionnaires to be analysed.

The ages of the participants ranged from 19 to 37 years old, with a mean of $24.38 \pm 2.37$. Majority of the students were in the age group 21-25 years (72.5\%). As shown in Table 1, most of the respondents were males (86.6\%) and only $13.4 \%$ were females. Majority of the respondents were single (89.3\%), while few were married (10.7\%). Somalia had the highest respondents, with $74.5 \%$, followed by Nigeria with $22.1 \%$. Turkey constituted $2 \%$, while $1.3 \%$ respondents were from Nepal. More than half of the students were doing a master's program (58.4\%), while undergraduates accounted for less than half (41.6\%). Among all the respondents, most were funded by their families (85.9\%). Others were self-funded (12.8\%), and only a few (1.3\%) were funded by scholarship. Those living alone were few (11.4\%) compared to those living with others $(88.6 \%)$, while those comfortable with their living conditions were more $(71.8 \%)$ as against those who were uncomfortable (28.2\%).

${ }^{* *}$ Pearson's Correlation using both Age and CESD scores as ungrouped quantitative variables

Prevalence of depressive symptoms was $47.7 \%$ based on the CESD Score (more than 10 scores), while $52.3 \%$ had no depressive symptoms (less than 10 scores). The mean CESD Score was $9.66 \pm 4.36$. Socio-demographic factors found to be associated with depression were age, marital status and satisfaction with living conditions (Figure 1).

Among the international students, less than half had problems concerning their studies (42\%), while the majority (57.7\%) had no problems concerning studies. Majority of those with problems was regarding language barriers.

A vast majority of the international students have encountered problems while living in Bangladesh (83.9\%). Among those who encountered problems, more than two-thirds had the problem of adapting to Bangladeshi foods and homesickness. Accommodation problems were encountered by almost half (45.6\%). Financial difficulty and health problems accounted for about more than one-third of cases $(38.4 \%$ and $34.4 \%$, respectively). All problems were significantly associated with depression (Table 2).

Concerning academic performance measured by Cumulative Grade Point Average (CGPA), more than half had CGPA of 3.0-3.49 (55\%). Students with CGPA of 3.5-4.0 were about one fourth (26.8\%), while the least CGPA group of 2.5-2.99 were the smallest group (17.4\%). No student rated the quality of studies as poor. All the students ranked the quality of education at the university as very good or good $(57.7 \%$ or $42.3 \%$ respectively). Most students indicated full cooperation from their teachers regarding their studies (72.5\%). Others reported fair collaboration (25.5\%), while only a few (2\%) felt they had poor cooperation from their teachers. There was a significant relationship between academic performance and depressive symptoms, $\mathrm{P}=0.000$ (Table 3 ).

\section{DISCUSSION}

Several pieces of research among International Students have shown depression is common among them (Khawaja and Dempsey, 2007; Hahn 2010; Ibrahim et al., 2013; Eskanadrieh et al., 2013). This study revealed that nearly half of the international students had depressive symptoms (47.7\%). We also explored the relationship between socio-demographic characteristics and depressive symptoms. Findings indicated that students' age, marital status and satisfaction with living conditions were significantly associated with depressive symptoms $(\mathrm{P}=0.018$, $0.020 \& 0.000$ respectively). Depressive symptoms were more as age increased and more among married students and those dissatisfied with their living conditions.

Similarly, a study by Sümer et al. (2008) on predictors of anxiety and depression among international students showed age significantly contributed to the variance in depression and anxiety. Research into marital status and depression has tended to support the view that those in a marriage report lower rates of depression and higher levels of well-being than single individuals in the general population (Inaba et al., 2005). A common explanation is that marriage shields people from 
Table 1. Association between Socio Demographic Factors and Depressive Symptoms.

\begin{tabular}{|c|c|c|c|c|}
\hline Variables & $\begin{array}{c}\text { Depressive symptoms } \\
\mathrm{n}(\%)\end{array}$ & $\begin{array}{c}\text { No Depressive symptoms } \\
\mathrm{n}(\%)\end{array}$ & $\begin{array}{l}\text { Total } \\
\mathrm{n}(\%)\end{array}$ & P-value \\
\hline \multicolumn{5}{|l|}{ Age (years) } \\
\hline $16-20$ & $3(50 \%)$ & $3(50 \%)$ & $6(4.8 \%)$ & \multirow{4}{*}{0.018} \\
\hline $21-25$ & $47(43.5 \%)$ & $61(56.5 \%)$ & $108(72.4 \%)$ & \\
\hline $26-30$ & $19(57.6 \%)$ & $14(42.4 \%)$ & $33(22.1 \%)$ & \\
\hline $31-35$ & $1(100 \%)$ & $0(0.0 \%)$ & $1(0.7 \%)$ & \\
\hline \multicolumn{5}{|l|}{ Gender } \\
\hline Male & $61(46.9 \%)$ & $69(53.1 \%)$ & $130(87.2 \%)$ & \multirow[b]{2}{*}{0.642} \\
\hline Female & $10(52.6 \%)$ & $9(47.4 \%)$ & $19(12.8 \%)$ & \\
\hline \multicolumn{5}{|l|}{ Marital Status } \\
\hline Single & $59(44 \%)$ & $74(56 \%)$ & $133(89.3 \%)$ & \multirow[b]{2}{*}{0.020} \\
\hline Married & $12(75 \%)$ & $4(25 \%)$ & $16(10.7 \%)$ & \\
\hline \multicolumn{5}{|l|}{ Country of origin } \\
\hline Nepal & $1(50 \%)$ & $1(50 \%)$ & $2(1.3 \%)$ & \multirow[b]{4}{*}{0.601} \\
\hline Nigeria & $19(57.5 \%)$ & $14(42.5 \%)$ & $33(22.1 \%)$ & \\
\hline Somalia & $50(45 \%)$ & $61(55 \%)$ & $111(74.5 \%)$ & \\
\hline Turkey & $1(33.3 \%)$ & $2(66.6 \%)$ & $3(2 \%)$ & \\
\hline \multicolumn{5}{|l|}{ Degree Category } \\
\hline Undergraduate & $26(41.9 \%)$ & $36(58.1 \%)$ & $62(41.6 \%)$ & \multirow[b]{2}{*}{0.238} \\
\hline Postgraduate & $45(51.7 \%)$ & $42(48.3 \%)$ & $87(58.4 \%)$ & \\
\hline \multicolumn{5}{|l|}{ Funding } \\
\hline Scholarship & $2(100 \%)$ & $0(0.0 \%)$ & $2(1.3 \%)$ & \multirow[b]{3}{*}{0.082} \\
\hline Self-funded & $12(63.1 \%)$ & $7(36.9 \%)$ & $19(12.8 \%)$ & \\
\hline Family support & $57(44.5 \%)$ & $71(55.5 \%)$ & $128(85.9 \%)$ & \\
\hline \multicolumn{5}{|l|}{ Residence } \\
\hline Living alone & $9(52.9 \%)$ & $8(47.1 \%)$ & $17(11.4 \%)$ & \multirow[b]{2}{*}{0.643} \\
\hline Living with others & $62(46.9 \%)$ & $70(53.1 \%)$ & $132(88.6 \%)$ & \\
\hline \multicolumn{5}{|l|}{ Living satisfaction } \\
\hline Uncomfortable & $32(76.1 \%)$ & $10(23.9 \%)$ & $42(28.2 \%)$ & \multirow[b]{2}{*}{0.000} \\
\hline Comfortable & $39(35.8 \%)$ & $68(64.2 \%)$ & $107(71.8 \%)$ & \\
\hline
\end{tabular}

*'With Spouse', 'With Friends', etc.

Table 2. Problems Encountered by Respondents and Association with Depression.

\begin{tabular}{|c|c|c|c|}
\hline Problems & With depressive symptoms f (\%) & No depressive symptoms f (\%) & P-value \\
\hline Academics & $40(61.5 \%)$ & $23(38.5 \%)$ & 0.001 \\
\hline Bangladeshi food & $54(63.5 \%)$ & $31(36.5 \%)$ & 0.000 \\
\hline Accommodation & $33(57.8 \%)$ & $24(42.2 \%)$ & 0.049 \\
\hline Homesickness & $50(61 \%)$ & $32(39 \%)$ & 0.000 \\
\hline Financial & $43(89.6 \%)$ & $5(10.4 \%)$ & 0.000 \\
\hline Health & $30(69.8 \%)$ & $13(30.2 \%)$ & 0.001 \\
\hline
\end{tabular}

the effects of stress, due to higher levels of protective resources provided by the relationship, such as intimacy and emotional support, however, in this study, only $6.2 \%$ of those who were married lived with their spouses, while most of them had left their spouses in their country of origin. This may explain the higher level of depression among married students in this population, consistent with research done by Yue among Chinese international students in Syracuse University (Zhang, 2012). Dissatisfaction with living conditions was strongly associated with having depression among international 
Table 3. Association between Academic performance (CGPA) and Depression.

\begin{tabular}{|c|c|c|c|c|}
\hline CGPA & With depression $\mathbf{f}(\%)$ & No depression $\mathbf{f}(\%)$ & Total $\mathbf{f}(\%)$ & P-value \\
\hline $2.5-2.99$ & $22(84.6)$ & $4(15.4)$ & $26(17.4)$ & \\
\hline $3.0-3.49$ & $30(36.1)$ & $53(63.9)$ & $83(55.7)$ & 0.000 \\
\hline $3.5-4.0$ & $19(47.5)$ & $21(52.5)$ & $40(26.8)$ & \\
\hline Total & $71(47.7)$ & $78(52.3)$ & $149(100)$ & \\
\hline
\end{tabular}

students in this study. This is consistent with previous research as satisfaction with one's living environment is believed to provide a buffer against poor mental health in everyday life (Christie et al., 2002), while dissatisfaction with ones living arrangement may cause additional strain and pose a significant risk to well-being (Chow, 2005).

All other characteristics analysed (gender, country of origin, degree category, source of funding) appeared to have no significant relationship with having depressive symptoms (Table 1). In a previous research among international students in the Philippines, sex, course category, year level, nationality, and religion, among others, were not statistically significant factors (Lee et al., 2013). This means that international university students, notwithstanding these social and demographic characteristics, were highly similar in their levels of depressive symptoms (Lee et al., 2013).

Regarding the nature of problems encountered in the study, the problems most encountered were language barrier and teaching methods. For those who have difficulties with the English language, it can be a significant contributing factor in doing poorly in the classroom, especially in classes where the student is expected to comprehend lectures, speak up, write papers and take essay exams. While almost half of the students encountered some accommodation problems, a greater majority faced problems of adapting to food and homesickness (Table 2). Financial and health problems were less prevalent. In this study, most international students were supported by their families, so the financial problem was not as severe in the group as in other international students. Findings from a qualitative research study conducted in the United Kingdom suggested that international students would experience positive feelings of comfort and safety when they are served with familiar food of their home country (Brown et al., 2010). According to Eskanadrieh et al. (2012), burden of homesickness is inevitably stressful and can lead to mental problems. A study conducted by Kwon on factors affecting international students' transition to higher education institutions in the United States also provided empirical evidence about the financial needs of international students (Kwon, 2009). Linked to the financial situation is the type of accommodation a student can afford. For students living in rental accommodation, poor quality housing has been found to reduce psychological well-being. International students may experience health problems due to changes in living conditions and stress.

All problems enumerated appeared to have a significant relationship with having depressive symptoms with the most substantial being problem with food, homesickness and financial difficulty $(\mathrm{p}=0.000)$, as shown in Table 2 . Previous researches are consistent with these findings (Sharareh et al., 2012; Lee et al., 2013; Brown et al., 2010; Andrew \& Wilding, 2004). Furthermore, this study found a significant association between academic performance and depressive symptoms, which several researchers have found to be negatively associated (Khurshid et al., 2015; Owens et al., 2012; Al-Qaisy, 2011; Jones, 2008).

\section{LIMITATIONS:}

Depression symptoms were measured by self-report rather than a clinical interview; although the limitation is mitigated by the generally accepted quality of the CES-D as a clinical screen, a depressive score of 10 is not assumed to have clinical depression. Future research of this nature should consider using clinical interviews to augment self-report measures. The study population was limited to international students of a single university and may not be representative of all international students of the country. Besides, due to the limited sample size, complicated multivariable statistics were not performed.

More studies with larger populations and more heterogeneous population are advised to be conducted on international student populations in Bangladesh. Other factors affecting depression, for example, previous episodes of depression or family history of depression were not taken into account. Consequently, it is difficult to discern what peripheral factors, if any, contributed to the presence of self-reported depressive symptoms. Subsequent research could include pre, during and post school assessments of depression symptoms. 


\section{CONCLUSION}

The results from this study have shown that the prevalence of depressive symptoms among international students of Daffodil International University is $47.7 \%$. Several problems faced by these students like academic, food, homesickness, financial and health problems were identified, and those problems were found to have a significant relationship with having symptoms of depression and also significant association was found between academic performance and depression.

\section{RECOMMENDATIONS}

From the above findings, it is necessary to act on recommendations to alleviate the burden of depression among international students to ease their academic sojourn. Universities should provide extensive pre-arrival information and an orientation event on arrival that may last up to a week, which are designed to prepare them for the experience of the new environment. International students, especially Africans, face a significant problem of securing accommodation. There is mistrust by the indigenes towards foreigners, which makes it very hard to find accommodation, especially for a single bachelor. Even if it is available, there is financial exploitation in terms of rent. There is a need for the university to arrange hostels, especially for international students to get settled on arrival. It is also essential to address the widespread lack of knowledge amongst international students about what is expected of them regarding the style and standard of academic submissions. They should make the provision of guidelines on this subject a priority. These could include, for example, instructions on answering questions in exams, which should be strictly adhered to by students and when marking by teachers. Many international students would be unfamiliar with the teaching methods used in foreign universities. The academic and supporting staff need to be fully aware of the indicators that suggest a student is in distress. Some will be more evident to academic staff, others to staff in residences or to peers. Signs may include erratic attendance or unexplained absence, disinterest in personal appearance, avoidance of participation in class, or withdrawal from social contact, changes in academic performance, drug abuse or problematic drinking; or health complaints, such as headaches, memory lapses, poor concentration and tiredness. It is useful for students to have information about the range of medical services available and how these are accessed via the provision of the school clinic, including information about dentists, opticians, and other specialists. There is need for academics/personal tutors, counselling services, health services, financial and welfare services, chaplaincy, international student advisers, Students' Union advisers, teaching support staff, disability advisers, mental health advisers and careers advisers. A short information leaflet giving explanations of concepts such as psychiatry, psychotherapy, psychology and counselling would be useful. Such a leaflet could be distributed to all international students on arrival. Alternatively, institutions could direct international students to web-based information on mental health issues. Mental health services should be made available in the University clinic.

\section{ACKNOWLEDGMENTS}

The authors would like to thank the Department of Public Health, Daffodil International University, Dhaka Bangladesh and Department of Medicine, Universiti Tunku Abdul Rahman, Kuala Lumpur, Malaysia.

\section{COMPETING INTERESTS}

The authors declare that they have no competing interests. Dr Yasir Arafat is member of the editorial board, he had no influence on the acceptance of the paper.

\section{FUNDING}

No funding was received to conduct the research.

\section{INFORMED CONSENT}

Informed consent was obtained from each participant prior to data collection.

\section{ETHICAL APPROVAL}

The study was approved by the academic committee of the Department of Public Health of Daffodil International University 


\section{REFERENCES}

Andrews, B. and Wilding, J.M. 2004. The relation of depression and anxiety to life $\square$ stress and achievement in students. British Journal of Psychology, 95(4), pp. 509-521.

Al-Qaisy, L.M. 2011. The relation of depression and anxiety in academic achievement among group of university students. International Journal of Psychology and Counselling, 3(5), pp. 96-100.

Brown, L., Edwards, J. and Hartwell, H. 2010. A taste of the unfamiliar. Understanding the meanings attached to food by international postgraduate students in England. Appetite, 54(1), pp. 202-207.

Chow, H.P. 2005. Life satisfaction among university students in a Canadian prairie city: A multivariate analysis. Social indicators research, 70(2), pp. 139-150.

Christie, H., Munro, M. and Rettig, H. 2002. Accommodating students. Journal of Youth Studies, 5(2), pp. 209-235.

CESD-R (2004). CES-D Scale. [Online] Available from: Cesd-r.com [Accessed on 15/06/2015]

Eskanadrieh, S., Liu, Y., Yamashina, H., Kono, K., Arai, A., Lee, R.B. and Tamashiro, H., 2012. Depressive symptoms among international university students in northern Japan: Prevalence and associated factors. Kokusai Hoken Iryo (Journal of International Health), 27(2), pp. 165-170.

Hahn, Z.L.2010. Coping with acculturative stress and depression among international students: A cultural perspective (Doctoral dissertation, University of Pennsylvania).

Ibrahim, A. K., Kelly, S. J., Adams, C. E. and Glazebrook, C. 2013. A systematic review of studies of depression prevalence in university students. Journal of Psychiatric Research, 47 (3), 391-400.

Inaba, A., Thoits, P.A., Ueno, K., Gove, W.R., Evenson, R.J. and Sloan, M., 2005. Depression in the United States and Japan: gender, marital status, and SES patterns. Social science \& medicine, 61(11), pp. 2280-2292.

Jones, R.C., 2008. The effects of depressed mood on academic outcomes in adolescents and young adults (Doctoral dissertation, University of South Florida).
Khan, M.S., Mahmood, S., Badshah, A., Ali, S.U. and Jamal, Y.2006. Prevalence of depression, anxiety and their associated factors among medical students in Karachi, Pakistan. Journal-Pakistan Medical Association, 56(12), p. 583.

Khawaja, N., \& Dempsey, J. 2007. Psychological Distress in International University Students: An Australian Study. Australian Journal of Guidance and Counselling, 17(1), 13-27.

Khurshid, S., Parveen, Q., Yousuf, M.I. and Chaudhry, A.G. 2015. Effects of depression on students' academic performance. Science International, 27(2), pp. 1619-1624.

Kwon, Y. 2009. Factors Affecting International Students' Transition To Higher Education Institutions In The United States. From the perspective of Office of International Students. College Student Journal, 43(4).

Lee, R.B., Maria, M.S., Estanislao, S. \& Rodriguez, C.2013. Factors Associated with Depressive Symptoms among Filipino University Students. PLoS ONE 8(11): e79825.

OECD.2013. Education Indicators in focus. [Online] Available from: http://www.oecd.org/education/skills-beyond-school/EDIF\%20 2013--N¹4\%20(eng)-Final.pdf [Accessed on 17/06/2015]

Owens, M., Stevenson, J., Hadwin, J.A. and Norgate, R.2012. Anxiety and depression in academic performance: An exploration of the mediating factors of worry and working memory. School Psychology International, 33(4), pp. 433-449.

Sümer, S., Poyrazli,S., \& Grahame, K.2008.Predictors of depression and anxiety among international students. Journal of Counselling and Development, 86; 429-437.

Thakar, D.A., 2010. Trajectories of Mental Health and Acculturation among First Year International Graduate Students from India. ProQuest LLC.

WHO. 2018. Fact sheet on Mental Disorders. [Online] Available from: www.who.int/en/news-room/fact-sheets/detail/mentaldisorders [Accessed on 17/06/2018]

Zhang, Y.2012. An examination of acculturative stress, perceived social support and depression among Chinese international students (Doctoral dissertation, Syracuse University). 